Check for updates

Cite this: RSC Adv., 2020, 10, 33450

Received 11th August 2020

Accepted 1st September 2020

DOI: $10.1039 / \mathrm{dOra06913b}$

rsc.li/rsc-advances

\section{Regio- and stereoselective thiocyanatothiolation of alkynes and alkenes by using $\mathrm{NH}_{4} \mathrm{SCN}$ and $\mathrm{N}$ - thiosuccinimides $\uparrow$}

\author{
Liang Qi, ${ }^{a}$ Shiwen Liu $^{b}$ and Linxia Xiao (D) *a
}

\begin{abstract}
A highly regioselective thiocyanatothiolation of alkynes and alkenes assisted by hydrogen bonding under simple and mild conditions is developed. Our thiocyanatothiolation reagents are readily available ammonium thiocyanate and $\mathrm{N}$-thiosuccinimides. This metal-free system offers good chemical yields for a wide range of alkyne and alkene substrates with good functional group tolerance.
\end{abstract}

Sulfur-containing molecules are ubiquitous structural motifs and widely exist in natural products, ${ }^{1,2}$ pharmaceuticals ${ }^{3,4}$ and agrochemicals. $^{5-7}$ Examples include the nonsteroidal antiinflammatory drug Sulindac, ${ }^{8}$ the basal-cell carcinoma treatment drug Vismodegib, ${ }^{9}$ and drugs for the treatment of Parkinson's disease..$^{10}$ Therefore, efficient introduction of sulfur into organic molecules has drawn much attention. ${ }^{11-15}$ And numerous approaches for the formation of $\mathrm{C}-\mathrm{S}$ bonds have been developed..$^{16-20}$ The most used organosulfur sources for the formation of C-S bonds are thiols and thiophenols, which have an unpleasant smell. Recently, inorganic metal sulfides have been extensively used to construct $\mathrm{C}-\mathrm{S}$ bonds, such as sodium metabisulfite, ${ }^{21} \mathrm{~K}_{2} \mathrm{~S},{ }^{22} \mathrm{Na}_{2} \mathrm{~S}^{23}$ and $\mathrm{Na}_{2} \mathrm{~S}_{2} \mathrm{O}_{3} .{ }^{24}$ Compared to thiols and thiophenols, inorganic metal sulfides are cheaper and generally stable. Thus, introduction of sulfur-containing groups into molecules by using inorganic metal sulfides is one of the desired approaches. Among them, thiocyanates commonly serve as important precursors for the preparation of thioethers, ${ }^{25}$ trifluoromethyl sulfides, ${ }^{26}$ heteroaromatic compounds. ${ }^{27}$ In general, the sources of SCN used to introduce a sulfur-containing group into molecules are thiocyanate salts ${ }^{28-35}$ such as KSCN, NaSCN, AgSCN and $\mathrm{NH}_{4} \mathrm{SCN}$. For example, thiocyanate salts were employed in thiocyanation of bromoalkenes via photocatalysis (Scheme 1a). ${ }^{36}$ Besides, the vinyl thiocyanates could be also obtained by thiocyanation of haloalkynes (Scheme 1b), ${ }^{37}$ iodothiocyanation of alkynes (Scheme 1c). ${ }^{38}$ Obviously, difunctionalization of alkynes is the most straightforward protocol to prepare vinyl thiocyanates.

aJiangsu Vocational College of Medicine, Jie Fang South Road 283 th, Yancheng, 224000, China. E-mail: xiaolinxiaxlx@126.com

${ }^{b}$ College of Textiles and Clothing, Yancheng Institute of Technology, Yancheng, 224051, China

$\dagger$ Electronic supplementary information (ESI) available. CCDC 2022664. For ESI and crystallographic data in CIF or other electronic format see DOI: 10.1039/d0ra06913b
Recently, our group has focused on hydrogen-bonding network or cluster ${ }^{39}$ assisted transformations such as hydrofluorination of ynamides ${ }^{40}$ and alkenes, ${ }^{41}$ the addition of sulfonic acids to haloalkynes, ${ }^{42}$ fluorothiolation of alkenes, ${ }^{20}$ dihalogenation of alkynes ${ }^{43}$ and hydrochlorination of alkyne$\mathrm{s},{ }^{44-46}$ halothiolation of alkynes. ${ }^{47}$ Along this line, herein, we are glad to report a hydrogen bond network-enabled regio- and stereoselective thiocyanatothiolation of alkynes using $\mathrm{NH}_{4} \mathrm{SCN}$ and $N$-thiosuccinimides.

Initially, according to the previous report, ${ }^{20}$ we started the investigation of thiocyanatothiolation protocol using $\mathrm{NH}_{4} \mathrm{SCN}$ and $N$-(phenylthio)succinimide as thiolation reagents in DCM under air and carried out the reaction at $60^{\circ} \mathrm{C}$ (Table 1). To our delight, the desired product $3 \mathrm{a}$ was obtained in $42 \%$ yield
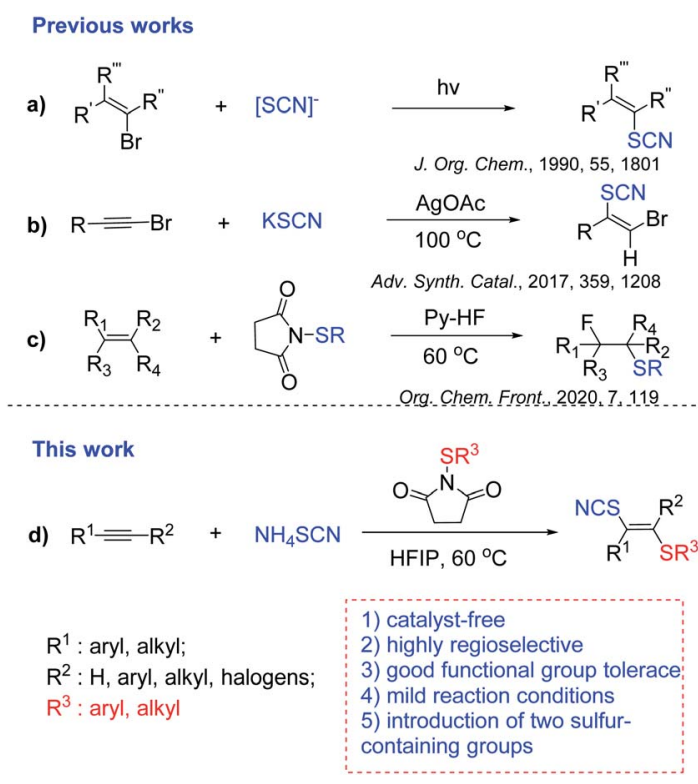

Scheme 1 Methods for thiocyanatothiolation of alkynes and alkenes. 
Table 1 Optimization for the reaction conditions

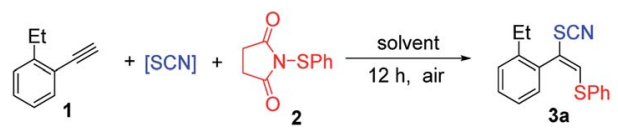

\begin{tabular}{|c|c|c|c|c|}
\hline Entry $^{a}$ & {$[\mathrm{SCN}]$} & Solvent & Temp. $\left({ }^{\circ} \mathrm{C}\right)$ & Yield $^{b}(\%)$ \\
\hline 1 & $\mathrm{NH}_{4} \mathrm{SCN}$ & DCM & 60 & 42 \\
\hline 2 & $\mathrm{NH}_{4} \mathrm{SCN}$ & DCE & 60 & 47 \\
\hline 3 & $\mathrm{NH}_{4} \mathrm{SCN}$ & THF & 60 & 0 \\
\hline 4 & $\mathrm{NH}_{4} \mathrm{SCN}$ & Acetone & 60 & 0 \\
\hline 5 & $\mathrm{NH}_{4} \mathrm{SCN}$ & $\mathrm{DMF}$ & 60 & 0 \\
\hline 6 & $\mathrm{NH}_{4} \mathrm{SCN}$ & iPrOH & 60 & 0 \\
\hline 7 & $\mathrm{NH}_{4} \mathrm{SCN}$ & $\mathrm{AcOH}$ & 60 & 24 \\
\hline 8 & $\mathrm{NH}_{4} \mathrm{SCN}$ & TFE & 60 & 18 \\
\hline 9 & $\mathrm{NH}_{4} \mathrm{SCN}$ & HFIP & 60 & 87 \\
\hline 10 & LiSCN & HFIP & 60 & 36 \\
\hline 11 & NaSCN & HFIP & 60 & 42 \\
\hline 12 & KSCN & HFIP & 60 & 49 \\
\hline 13 & $\mathrm{NH}_{4} \mathrm{SCN}$ & HFIP & 25 & 63 \\
\hline 14 & $\mathrm{NH}_{4} \mathrm{SCN}$ & HFIP & 80 & 83 \\
\hline
\end{tabular}

${ }^{a}$ Reaction conditions: 1 (0.1 mmol), 2 (0.12 mmol), NH $\mathrm{NCN}_{4}(0.2$ mmol), solvent $(0.5 \mathrm{~mL})$, under air for $12 \mathrm{~h}$ at $60^{\circ} \mathrm{C} .{ }^{b}$ Determined by GC.

without any isomers found in the reaction mixture detected by GC-MS (Table 1, entry 1). Screening of solvents indicated that this transformation could not proceed in the polar solvents, such as acetone, THF, dioxane, i-PrOH, DMF (Table 1, entries 36) probably due to the solvation of electrophiles while moderate yield could be obtained in non-polar solvent (Table 1, entry 2). Strong hydrogen-bond donor solvents such as hexafluoro-2propanol (HFIP), could form an H-bond network activating the electrophiles through a strong hydrogen bonding interaction. ${ }^{48}$ In order to enhance the H-bond interaction between the hydroxyl and 2, so AcOH was chosen to compare with HFIP (Table 1, entry 7). Along this line, hydrogen-bond donor solvents were used and further optimization of hydrogen-bond donor solvents indicated that HFIP was superior to AcOH and trifluoroethanol (Table 1, entries 7-9). Moreover, a screening of thiocyanate salts showed that $\mathrm{NH}_{4} \mathrm{SCN}$ was the best SCN source for this transformation compared with lithium thiocyanate, sodium thiocyanate and potassium thiocyanate (Table 1, entries 10-12). Additionally, decreasing the temperature from $60^{\circ} \mathrm{C}$ to room temperature resulted in a lower yield (Table 1 , entry 13 ) and the reaction yield was not improved significantly by raising the temperature from $60{ }^{\circ} \mathrm{C}$ to $80^{\circ} \mathrm{C}$ (Table 1 , entry 14).

With the optimized conditions in hand, we next turned our attention to explore the substrate scope (Table 2). Firstly, $N$-( $p$ methoxyphenylthio)succinimide was used as electrophile to explore the scope of alkynes. In general, the reaction proceeded well to provide the desired products 3 in moderate to excellent yields with satisfactory regio- and stereoselectivity. Diverse aryl alkynes containing electron-donating groups such as isopropyl, hydroxy, methoxy, hydroxyethyl, tert-butyl and trifluoromethoxy groups (Table 2, $\mathbf{3 e - 3} \mathbf{g}$ and $\mathbf{3 m - 3} \mathbf{m}$ ) at the ortho, meta, or para positions of aryl rings all reacted with $N$-thiosuccinimides to
Table 2 Scope for thiocyanatothiolation of alkynes and $N$ arylsulfenylsuccinimides ${ }^{a, b}$

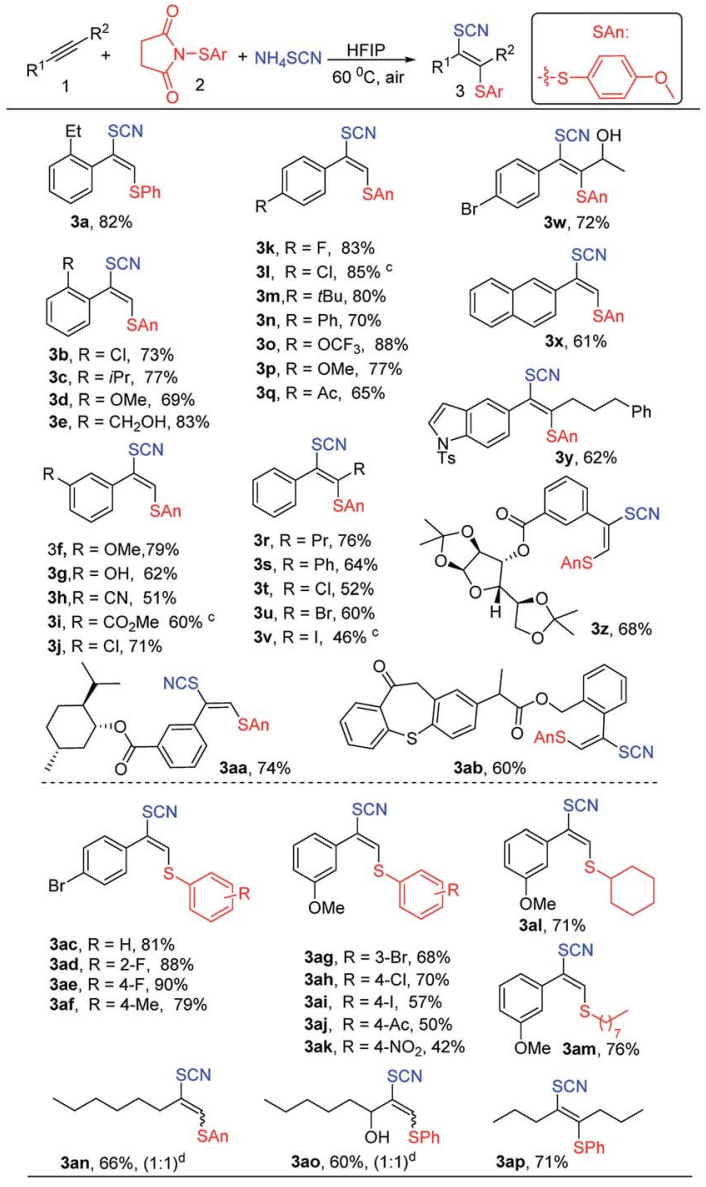

${ }^{a}$ Reaction conditions: 1 (0.1 mmol), 2 (0.12 mmol), $\mathrm{NH}_{4} \mathrm{SCN}(0.2$ $\mathrm{mmol})$, HFIP $(0.5 \mathrm{~mL})$, under air for $12 \mathrm{~h}$ at $60{ }^{\circ} \mathrm{C} .{ }^{b}$ Isolated yield. ${ }^{c} \mathrm{Ar}=\mathrm{Ph} .{ }^{d}$ Determined by NMR.

give the corresponding adducts in moderate to excellent yields. Besides, halide substitutes (F, Cl, Br) (Table 2, $\mathbf{3 b}, \mathbf{3} \mathbf{j}-\mathbf{3} \mathbf{l}$ and $\mathbf{3 w}$ ) and electron-withdrawing groups such as cyano and ester (Table 2, 3h and 3i) on phenyl ring were well tolerated. Furthermore, asymmetric or symmetrical internal alkynes also could be transformed into vinyl thiocyanates (Table 2, 3r, 3s and 3w) without any isomers. Remarkably, vinyl thiocyanates containing halogens could be obtained by using haloalkynes (Table 2, 3t3v). Additionally, slightly low yields were observed for fused aromatic such as naphthalene and heterocyclic aromatic (Table $2,3 \mathbf{x}$ and $3 \mathbf{y}$ ). Due to good functional-group tolerance, derivatives of diacetone-D-glucose (Table $2,3 \mathbf{z}$ ), natural products $\mathrm{L}^{-}$ menthol (Table 2, 3aa) and pharmaceuticals such as zaltoprofen (Table 2, 3ab) also worked well.

Next, we started to explore the scope of $\mathrm{N}$-arylsulfenylsuccinimides. Various $N$-arylsulfenylsuccinimides can be obtained easily by the method in ESI. $\dagger$ To our delight, the introduction of electron-donating groups or halide substitutes to the phenyl ring of $\mathrm{N}$-arylsulfenylsuccinimides had little influence on this 
Table 3 Scope for thiocyanatothiolation of alkenes ${ }^{a, b}$

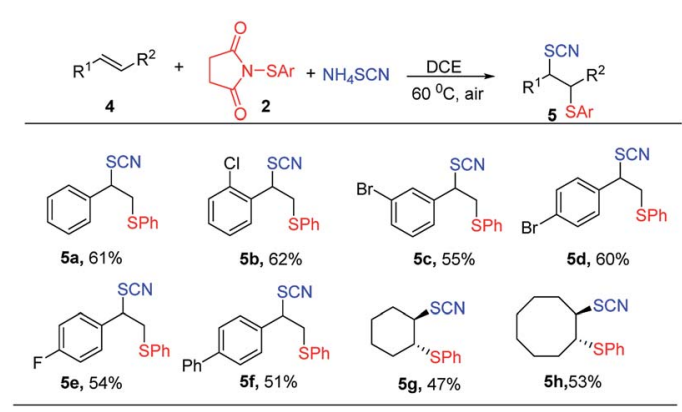

${ }^{a}$ Reaction conditions: $4(0.1 \mathrm{mmol}), 2(0.12 \mathrm{mmol}), \mathrm{NH}_{4} \mathrm{SCN}(0.2$ mmol), DCE $(1.0 \mathrm{~mL})$, under air for $12 \mathrm{~h}$ at $60^{\circ} \mathrm{C} .{ }^{b}$ Isolated yield.

reaction, providing the corresponding products in 57-90\% yields (Table 2, 3ac-3ak) while electron-withdrawing groups on the phenyl ring such as acetyl or nitro resulted in lower yields (Table 2, 3aj and 3ak) probably due to the decrease of electrophilicity of $\mathrm{N}$-arylsulfenylsuccinimides. Notably, the scope of $\mathrm{N}$ sulfenylsuccinimides could be extended to $N$-alkylsulfenylsuccinimides (Table 2, 3al and 3am), affording the desired products with good yields and high selectivity. Unfortunately, the thiocyanatothiolated products (Table 2, 3an and 3ao) with poor stereoselectivity $(\mathrm{Z} / E=1: 1)$ were obtained when the unsymmetrically aliphatic alkynes were employed. We speculated that the steric hindrance of the aliphatic side chain maybe is small, resulting in a low $\mathrm{Z} / E$ ratios.

Encouraged by the success of thiocyanatothiolation of alkynes, we next turned our focus to the thiocyanatothiolation of alkenes. Under the optimized conditions, no product was observed. And the HFIP as nucleophile replaced the $\mathrm{NH}_{4} \mathrm{SCN}$, giving hexafluoroisopropanol thiolated product. As result, nonpolar solvent DCE was used to avoid the hexafluoroisopropanol thiolat of alkenes. To our delight, the thiocyanatothiolation of alkenes could proceed smoothly though moderate or lower chemical yields were obtained. Among them, aromatic alkenes

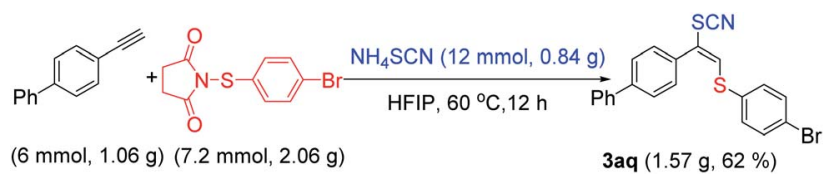

Scheme 2 Gram-scale preparation of 3aq.

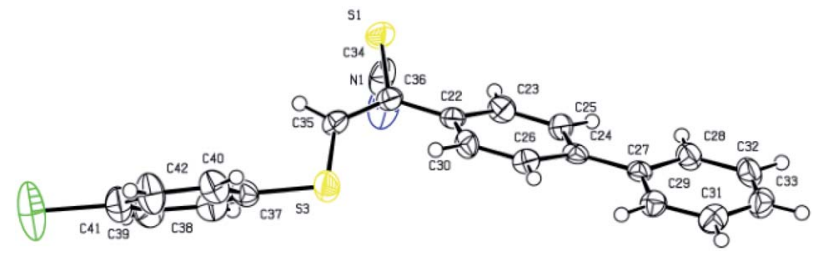

Fig. 1 Single crystal structure of 3aq.
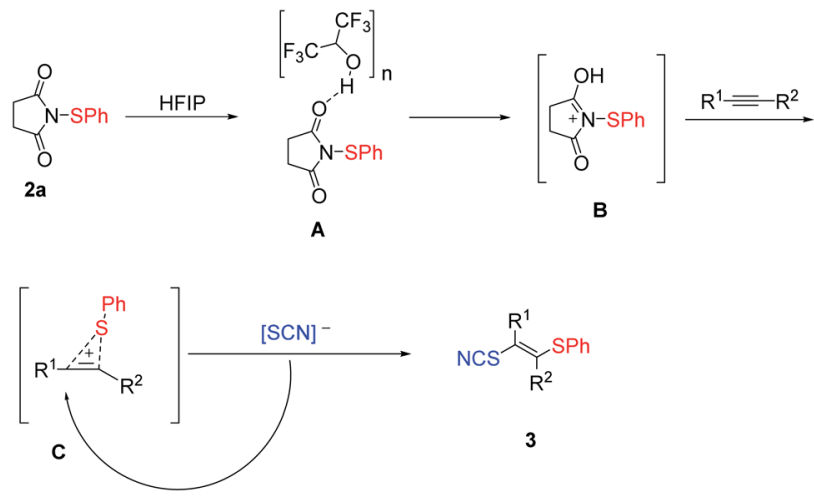

Scheme 3 Plausible mechanism.

gave moderate yields without any isomers (Table 3, 5a-5e) and aliphatic alkenes gave lower yields (Table $3, \mathbf{5 f}-\mathbf{5 h}$ ).

To demonstrate the scalability of this protocol, a gram-scale reaction of 1,1'-biphenyl-4-ethynyl ( $6 \mathrm{mmol})$ with $\mathrm{N}$-(4-bromo thio)succinimide was carried out, and the corresponding product 3aq was obtained in $62 \%$ yield (Scheme 2 ).

To identify the configuration, the single crystal of product 3aq was cultivated by solvent evaporation. And the regio- and stereoselectivity of products were further confirmed the X-ray crystallographic analysis of the obtained product 3aq (Fig. 1).

Based on our previous work, ${ }^{47}$ a plausible reaction pathway was proposed in Scheme 3. The interaction of HFIP hydrogen bonding linear aggregates ${ }^{48}$ with sulfenylation reagent 2 a may strongly activate the sulfenylation reagent, which generates the active intermediate $\mathbf{B}$ (Scheme 3). Sequentially, a sulfonium $\mathbf{C}$ is produced from intermediate $\mathbf{B}$ with an alkyne, followed by a nucleophilic attack of SCN anion to obtain the products 3 .

\section{Conclusions}

In summary, we have developed a widely applicable regio- and stereoselective thiocyanatothiolation of alkynes and alkenes under simple and mild conditions. This metal-free system offers good chemical yields and functional group tolerance. At present, the fluorinated reagent HFIP, which is not a green solvent, is indeed a limitation of this method, but as scientific research continues, we believe that green fluorinated reagents can be discovered. Other similar thiolation systems are currently investigated in our laboratory.

\section{Conflicts of interest}

There are no conflicts to declare.

\section{Acknowledgements}

We are grateful to the National Science Foundation of China (NSFC-21672035), Jiangsu Vocational College of Medicine (20186104) and Jiangsu Provincial Higher Education Natural Science Foundation (19KJB350010) for financial support. 


\section{Notes and references}

1 M. Fontecave, S. Ollagnier-de-Choudens and E. Mulliez, Biological Radical Sulfur Insertion Reactions, Chem. Rev., 2003, 103, 2149-2166.

2 S. Oida, Y. Tajima, T. Konosu, Y. Nakamura, A. Somada, T. Tanaka, S. Habuki, T. Harasaki, Y. Kamai, T. Fukuoka, S. Ohya and H. Yasuda, Synthesis and Antifungal Activities of R-102557 and Related Dioxane-Triazole Derivatives, Chem. Pharm. Bull., 2000, 48, 694-707.

3 E. A. Ilardi, E. Vitaku and J. T. Njardarson, Data-Mining for Sulfur and Fluorine: An Evaluation of Pharmaceuticals To Reveal Opportunities for Drug Design and Discovery, $J$. Med. Chem., 2014, 57, 2832-2842.

4 I. P. Beletskaya and V. P. Ananikov, Transition-MetalCatalyzed $\mathrm{C}-\mathrm{S}, \mathrm{C}-\mathrm{Se}$, and $\mathrm{C}-\mathrm{Te}$ Bond Formation via Cross-Coupling and Atom-Economic Addition Reactions, Chem. Rev., 2011, 111, 1596-1636.

5 C. Jacob, E. Battaglia, T. Burkholz, D. Peng, D. Bagrel and M. Montenarh, Control of Oxidative Posttranslational Cysteine Modifications: From Intricate Chemistry to Widespread Biological and Medical Applications, Chem. Res. Toxicol., 2012, 25, 588-604.

6 J. E. Casida, Unexpected Metabolic Reactions and Secondary Targets of Pesticide Action, J. Agric. Food Chem., 2016, 64, 4471-4477.

7 J. E. Casida and K. A. Durkin, Pesticide Chemical Research in Toxicology: Lessons from Nature, Chem. Res. Toxicol., 2017, 30, 94-104.

8 A. A. Constantinescu, K. Caliskan, O. C. Manintveld, R. van Domburg, L. Jewbali and A. H. M. M. Balk, Weaning from inotropic support and concomitant beta-blocker therapy in severely ill heart failure patients: take the time in order to improve prognosis, Eur. J. Heart Failure, 2014, 16, 435-443.

9 A. M. Giannetti, H. Wong, G. J. P. Dijkgraaf, E. C. Dueber, D. F. Ortwine, B. J. Bravo, S. E. Gould, E. G. Plise, B. L. Lum, V. Malhi and R. A. Graham, Identification, Characterization, and Implications of Species-Dependent Plasma Protein Binding for the Oral Hedgehog Pathway Inhibitor Vismodegib (GDC-0449), J. Med. Chem., 2011, 54, 2592-2601.

10 S. F. Nielsen, E. Ø. Nielsen, G. M. Olsen, T. Liljefors and D. Peters, Novel Potent Ligands for the Central Nicotinic Acetylcholine Receptor: Synthesis, Receptor Binding, and 3D-QSAR Analysis, J. Med. Chem., 2000, 43, 2217-2226.

11 D. Huang, J. Chen, W. Dan, J. Ding, M. Liu and H. Wu, A Metal-Free Sulfenylation and Bromosulfenylation of Indoles: Controllable Synthesis of 3-Arylthioindoles and 2Bromo-3-arylthioindoles, Adv. Synth. Catal., 2012, 354, 2123-2128.

12 C. J. Nalbandian, E. M. Miller, S. T. Toenjes and J. L. Gustafson, A conjugate Lewis base-Brønsted acid catalyst for the sulfenylation of nitrogen containing heterocycles under mild conditions, Chem. Commun., 2017, 53, 1494-1497.
13 D. Zhu, Y. Gu, L. Lu and Q. Shen, NDifluoromethylthiophthalimide: A Shelf-Stable, Electrophilic Reagent for Difluoromethylthiolation, J. Am. Chem. Soc., 2015, 137, 10547-10553.

14 S. Song, Y. Zhang, A. Yeerlan, B. Zhu, J. Liu and N. Jiao, $\mathrm{Cs}_{2} \mathrm{CO}_{3}$-Catalyzed Aerobic Oxidative Cross-Dehydrogenative Coupling of Thiols with Phosphonates and Arenes, Angew. Chem., Int. Ed., 2017, 56, 2487-2491.

15 S. Vásquez-Céspedes, A. Ferry, L. Candish and F. Glorius, Heterogeneously Catalyzed Direct $\mathrm{C} \cdot \mathrm{H}$ Thiolation of Heteroarenes, Angew. Chem., Int. Ed., 2015, 54, 5772-5776.

16 S. Bhunia, G. G. Pawar, S. V. Kumar, Y. Jiang and D. Ma, Selected Copper-Based Reactions for $\mathrm{C}-\mathrm{N}, \mathrm{C}-\mathrm{O}, \mathrm{C}-\mathrm{S}$, and C-C Bond Formation, Angew. Chem., Int. Ed., 2017, 56, 16136-16179.

17 X. Li, L. Li, X. Mo and D. Mo, Transition-metal-free synthesis of thiocyanato- or nitro-arenes through diaryliodonium salts, Synth. Commun., 2016, 46, 963-970.

18 S. Liu, X. Zeng and B. Xu, Hydrogen-Bonding-NetworkAssisted Regioselective Trifluoromethylthiolation and Sulfenylation of Electron-Rich (Hetero)arenes, Asian J. Org. Chem., 2019, 8, 1372-1375.

19 S. Liu, X. Zeng and B. Xu, Regio- and stereoselective halothiolation of alkynes using lithium halides and $\mathrm{N}$ thiosuccinimides, Org. Chem. Front., 2020, 7, 1690-1695.

$20 \mathrm{~S}$. Liu, X. Zeng and B. Xu, Practical fluorothiolation and difluorothiolation of alkenes using pyridine-HF and $\mathrm{N}$ thiosuccinimides, Org. Chem. Front., 2020, 7, 119-125.

21 M. Wang, Q. Fan and X. Jiang, Metal-free construction of primary sulfonamides through three diverse salts, Green Chem., 2018, 20, 5469-5473.

22 W. Tan, C. Wang and X. Jiang, Green carbon disulfide surrogate via a combination of potassium sulfide and chloroform for benzothiazine-thione and benzothiazolethione construction, Org. Chem. Front., 2018, 5, 2390-2394.

23 J. Wei, Y. Li and X. Jiang, Aqueous Compatible Protocol to Both Alkyl and Aryl Thioamide Synthesis, Org. Lett., 2016, 18, 340-343.

24 J. T. Reeves, K. Camara, Z. S. Han, Y. Xu, H. Lee, C. A. Busacca and C. H. Senanayake, The Reaction of Grignard Reagents with Bunte Salts: A Thiol-Free Synthesis of Sulfides, Org. Lett., 2014, 16, 1196-1199.

25 F. Ke, Y. Qu, Z. Jiang, Z. Li, D. Wu and X. Zhou, An Efficient Copper-Catalyzed Carbon-Sulfur Bond Formation Protocol in Water, Org. Lett., 2011, 13, 454-457.

26 B. Exner, B. Bayarmagnai, F. Jia and L. J. Goossen, IronCatalyzed Decarboxylation of Trifluoroacetate and Its Application to the Synthesis of Trifluoromethyl Thioethers, Chem.-Eur. J., 2015, 21, 17220-17223.

27 V. Aureggi and G. Sedelmeier, 1,3-Dipolar Cycloaddition: Click Chemistry for the Synthesis of 5-Substituted Tetrazoles from Organoaluminum Azides and Nitriles, Angew. Chem., Int. Ed., 2007, 46, 8440-8444.

28 H. Yang, X.-H. Duan, J.-F. Zhao and L.-N. Guo, TransitionMetal-Free Tandem Radical Thiocyanooxygenation of Olefinic Amides: A New Route to SCN-Containing Heterocycles, Org. Lett., 2015, 17, 1998-2001. 
29 L.-N. Guo, Y.-R. Gu, H. Yang and J. Hu, Transition-metal free thiocyanooxygenation of functionalized alkenes: facile routes to SCN-containing dihydrofurans and lactones, Org. Biomol. Chem., 2016, 14, 3098-3104.

30 B. Chen, S. Guo, X. Guo, G. Zhang and Y. Yu, Selective Access to 4-Substituted 2-Aminothiazoles and 4-Substituted 5Thiocyano-2-aminothiazoles from Vinyl Azides and Potassium Thiocyanate Switched by Palladium and Iron Catalysts, Org. Lett., 2015, 17, 4698-4701.

31 Y. Chen, S. Wang, Q. Jiang, C. Cheng, X. Xiao and G. Zhu, Palladium-Catalyzed Site-Selective $\mathrm{sp}^{3} \quad \mathrm{C}-\mathrm{H}$ Bond Thiocyanation of 2-Aminofurans, J. Org. Chem., 2018, 83, 716-722.

32 L. Zhen, K. Yuan, X.-y. Li, C. Zhang, J. Yang, H. Fan and L. Jiang, Cascade Reaction of Propargyl Amines with $\mathrm{AgSCF}_{3}$, as Well as One-Pot Reaction of Propargyl Amines, $\mathrm{AgSCF}_{3}$, and Di-tert-butyl Peroxide: Access to Allenyl Thiocyanates and Allenyl Trifluoromethylthioethers, Org. Lett., 2018, 20, 3109-3113.

33 Y.-F. Zeng, D.-H. Tan, Y. Chen, W.-X. Lv, X.-G. Liu, Q. Li and H. Wang, Direct radical trifluoromethylthiolation and thiocyanation of aryl alkynoate esters: mild and facile synthesis of 3-trifluoromethylthiolated and 3-thiocyanated coumarins, Org. Chem. Front., 2015, 2, 1511-1515.

34 Q. Lin, W. Yang, Y. Yao, S. Chen, Y. Tan, D. Chen and D. Yang, Copper-Catalyzed Diastereoselective 1,2Difunctionalization of Oxabenzonorbornadienes Leading to $\beta$-Thiocyanato Thioethers, Org. Lett., 2019, 21, 7244-7247.

35 X. Zeng, B. Chen, Z. Lu, G. B. Hammond and B. Xu, Homogeneous and Nanoparticle Gold-Catalyzed Hydrothiocyanation of Haloalkynes, Org. Lett., 2019, 21, 2772-2776.

36 T. Kitamura, S. Kobayashi and H. Taniguchi, Photolysis of vinyl halides. Reaction of photogenerated vinyl cations with cyanate and thiocyanate ions, J. Org. Chem., 1990, 55, 1801-1805.

37 G. Jiang, C. Zhu, J. Li, W. Wu and H. Jiang, Silver-Catalyzed Regio- and Stereoselective Thiocyanation of Haloalkynes: Access to (Z)-Vinyl Thiocyanates, Adv. Synth. Catal., 2017, 359, 1208-1212.
$38 \mathrm{X}$. Zeng and L. Chen, Iodine-mediated regio- and stereoselective iodothiocyanation of alkynes in aqueous ethanol, Org. Biomol. Chem., 2018, 16, 7557-7560.

39 T. Steiner, The Hydrogen Bond in the Solid State, Angew. Chem., Int. Ed., 2002, 41, 48-76.

40 X. Zeng, J. Li, C. K. Ng, G. B. Hammond and B. Xu, (Radio) fluoroclick Reaction Enabled by a Hydrogen-Bonding Cluster, Angew. Chem., Int. Ed., 2018, 57, 2924-2928.

41 Z. Lu, X. Zeng, G. B. Hammond and B. Xu, Widely Applicable Hydrofluorination of Alkenes via Bifunctional Activation of Hydrogen Fluoride, J. Am. Chem. Soc., 2017, 139, 1820218205.

42 X. Zeng, S. Liu, Z. Shi and B. Xu, Hydrogen Bonding ClusterEnabled Addition of Sulfonic Acids to Haloalkynes: Access to Both (E)- and (Z)-Alkenyl Sulfonates, Org. Lett., 2016, 18, 4770-4773.

43 X. Zeng, S. Liu, Y. Yang, Y. Yang, G. B. Hammond and B. Xu, Regio- and Stereoselective Synthesis of 1,2-Dihaloalkenes Using In-Situ-Generated $\mathrm{ICl}, \mathrm{IBr}, \mathrm{BrCl}, \mathrm{I}_{2}$, and $\mathrm{Br}_{2}$, Chem, 2020, 6, 1018-1031.

44 R. Ebule, S. Liang, G. B. Hammond and B. Xu, ChlorideTolerant Gold(I)-Catalyzed Regioselective Hydrochlorination of Alkynes, ACS Catal., 2017, 7, 67986801.

45 X. Zeng, S. Liu, G. B. Hammond and B. Xu, HydrogenBonding-Assisted Brønsted Acid and Gold Catalysis: Access to Both (E)- and (Z)-1,2-Haloalkenes via Hydrochlorination of Haloalkynes, ACS Catal., 2018, 8, 904-909.

46 J. Oliver-Meseguer, A. Doménech-Carbó, M. Boronat, A. Leyva-Pérez and A. Corma, Partial Reduction and Selective Transfer of Hydrogen Chloride on Catalytic Gold Nanoparticles, Angew. Chem., Int. Ed., 2017, 56, 6435-6439.

47 S. Liu, X. Zeng and B. Xu, Regio- and stereoselective halothiolation of alkynes using lithium halides and $\mathrm{N}$ thiosuccinimides, Org. Chem. Front., 2020, 7, 1690-1695.

48 S. Henkel, M. C. Misuraca, P. Troselj, J. Davidson and C. A. Hunter, Polarisation effects on the solvation properties of alcohols, Chem. Sci., 2018, 9, 88-99. 